\title{
INMUNOTERAPIA EN MELANOMA: VACUNAS DE CÉLULAS DENDRÍTICAS
}

\author{
Ivan Lozada-Requena ${ }^{1,2, a}$, César Núñez ${ }^{2, b}$, José Luis Aguilar ${ }^{1, c}$
}

\begin{abstract}
RESUMEN
La presente es una revisión narrativa que muestra la información accesible a la comunidad científica sobre melanoma e inmunoterapia. Las células dendríticas tienen la capacidad de participar en la inmunidad innata y adaptativa, pero no son ajenas a la evasión inmune de los tumores. Conocer su biología y rol ha llevado a generar in vitro varios prospectos de vacunas celulares autólogas contra diversos tipos de cáncer en humanos y modelos animales; sin embargo, en vista de la poca eficiencia que han mostrado, se deben implementar estrategias para potenciar su capacidad natural ya sea a través de la coexpresión de moléculas clave para activar o reactivar al sistema inmune, en combinación con biosimilares o drogas quimioterapeúticas y no se debe descartar la acción de productos naturales como alternativa inmunoestimulante o adyuvante. Todos los tipos de inmunoterapía deberían medir el impacto de las células supresoras de origen mieloide, las que pueden atacar al sistema inmune y ayudar a la progresión tumoral, respectivamente. Esto puede reducir la actividad de las vacunas celulares y/o sus combinaciones pudiendo ser la diferencia entre el éxito o no de la inmunoterapia. Aunque en melanoma existen biosimilares aprobados por la Food and Drug Administration (FDA) no todos tienen el éxito esperado por lo que es necesario evaluar otras estrategias que incluyan vacunas celulares cargadas con péptidos antigénicos tumorales expresados exclusivamente o antígenos provenientes de extractos tumorales y sus respectivos adyuvantes.
\end{abstract}

Palabras clave: Células dendríticas; Melanoma; Vacunas; Uña de Gato (fuente: DeCS BIREME).

\section{MELANOMA IMMUNOTHERAPY: DENDRITIC CELL VACCINES}

\begin{abstract}
This is a narrative review that shows accessible information to the scientific community about melanoma and immunotherapy. Dendritic cells have the ability to participate in innate and adaptive immunity, but are not unfamiliar to the immune evasion of tumors. Knowing the biology and role has led to generate in vitro several prospects of autologous cell vaccines against diverse types of cancer in humans and animal models. However, given the low efficiency they have shown, we must implement strategies to enhance their natural capacity either through the coexpression of key molecules to activate or reactivate the immune system, in combination with biosimilars or chemotherapeutic drugs. The action of natural products as alternative or adjuvant immunostimulant should not be ruled out. All types of immunotherapy should measure the impact of myeloid suppressor cells, which can attack the immune system and help tumor progression, respectively. This can reduce the activity of cellular vaccines and/or their combinations, that could be the difference between success or not of the immunotherapy. Although for melanoma there exist biosimilars approved by the Food and Drug Administration (FDA), not all have the expected success. Therefore it is necessary to evaluate other strategies including cellular vaccines loaded with tumor antigenic peptides expressed exclusively or antigens from tumor extracts and their respective adjuvants.
\end{abstract}

Key words: Dendritic cells; Melanoma; Vaccines; Cat's claw (source: MeSH NLM).

\section{INTRODUCCIÓN}

Las células dendríticas (DC) fueron descubiertas por Steiman y Cohn en 1973 y deben su nombre a que pueden asumir una variedad de formas ramificadas $y$ constantemente se extienden y retraen ${ }^{(1,2)}$ (Figura 1). Las DC se derivan de la célula madre pluripotente o
Stem Cell localizada en la médula ósea, esta célula da lugar a una célula precursora mieloide que dará origen a las DC que llegan a los tejidos en estadio aún inmaduro, para luego llegar a los órganos linfoides periféricos como DC maduras, siempre y cuando sean estimuladas. Asimismo, se ha dado a conocer una vía más a través de un precursor linfoide que generaría una DC inmadura

\footnotetext{
Laboratorios de Inmunología \# 108, Laboratorio de investigación y Desarrollo, Facultad de Ciencieas y Filosofía, Universidad Cayetano Heredia. Lima, Perú Empresa de Investigación y Desarrollo en Cáncer (EMINDES) SAC. Lima, Perú.

a Magíster en ciencias; ${ }^{\mathrm{b}}$ médico cirujano; ${ }^{\mathrm{c}}$ médico cirujano, especialista en inmunología y reumatología

Recibido: : 12-09-14 Aprobado: 13-05-15
}

Citar como: Lozada-Requena I, Núñez C, Aguilar JL. Inmunoterapia en melanoma: vacunas de células dendríticas. Rev Peru Med Exp Salud Publica. 2015;32(3):555-64 


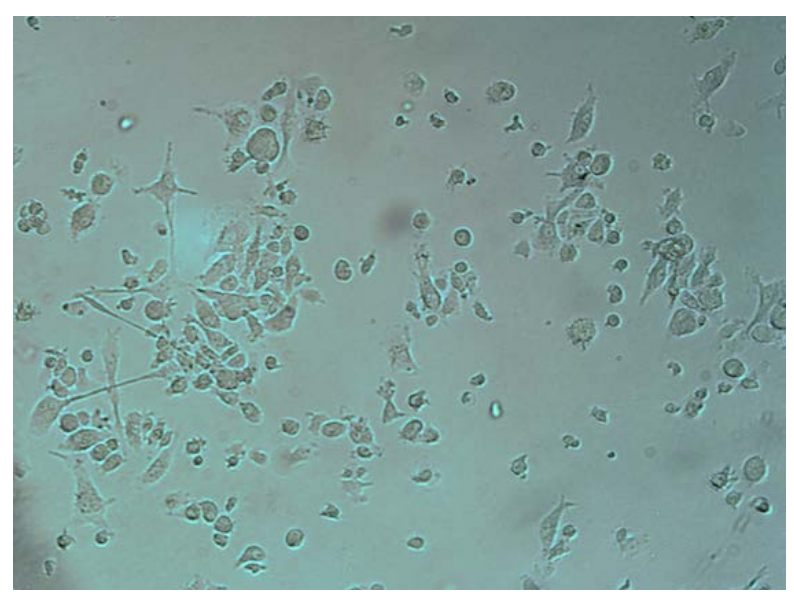

Figura 1. Diferenciación de células dendríticas. Se aislaron células progenitoras $\left(1 \times 10^{6}\right.$ células/pozo $)$ de la médula ósea de ratones C57/BL6, se cultivaron en medio RPMI-1640 completo suplementado con GM-CSF (40 ng/mL) durante 7 días. Las DC diferenciadas muestran un citoplasma irregular a manera de prolongaciones ramificadas. GM-CSF (Granulocyte-Monocyte Colonial Stimulate Factor); DC (células dendríticas). Foto: microscopio de luz invertida, 40x, Laboratorio de Inmunología \#108, UPCH.

que se encuentra en sangre y que en su estadio maduro llega a los órganos linfoides periféricos ${ }^{(3-5)}$.

En el estadio inmaduro las DC se destacan por su alta capacidad para la captura de antígenos, a través de endocitosis o fagocitosis, y su procesamiento usando las vías endógenas o exógenas del $\mathrm{MHC}$ I oll, respectivamente, que seguirá con la presentación antígeno-específica a los linfocitos T (LT), evento que las DC realizan paralelamente mientras llegan a su estadio maduro, por tal razón, se les ha denominado células presentadoras de antígeno profesionales (CPA), con mayor capacidad de captura, procesamiento y presentación de péptidos antígenicos, incluso que los macrófagos y los linfocitos $\mathrm{B}^{(4,6,7)}$.

Las DC también producen varias citoquinas y quimioquinas, tales como IL-12, IFN- $\gamma$, CCL5 y CCL21, las que tienen una variedad de funciones inmunorreguladoras, donde destaca la estimulación de los LT. Además, las DC son importantes en la regulación de la inmunidad innata y en el mantenimiento de la tolerancia central a LT ${ }^{(8-11)}$.

\section{CÉLULAS DENDRÍTICAS VERSUS CÁNCER}

La inmunovigilancia es un concepto que ha sido el punto de partida de muchas discusiones en relación a la inmunología de los tumores, pero que parece no ser suficiente para entender la respuesta antitumoral, ante esto, aparecen nuevos conceptos para explicar la complejidad y multidimensionalidad de la respuesta inmune a los tumores. La inmunoedición explica que existen tres fases en la evolución de un tumor con respecto al sistema inmune: la primera es la eliminación, en la que el sistema inmune es capaz de detectar y eliminar al tumor; la segunda se denomina equilibrio, en la que las células tumorales mantienen un equilibrio dinámico con el sistema inmune, pero que empieza a generar nuevas variantes del tumor $\mathrm{y}$, finalmente, la fase de escape, cuando esas variantes tumorales crecen indiscriminadamente hasta generar un tumor clínicamente detectable ${ }^{(12-15)}$. Un potencial mecanismo del que los tumores escapan es la presentación de antígenos tumorales por las CPA. Estudios in vitro demostraron que el sobrenadante de cultivo de líneas celulares cancerígenas contenia VEGF (factor de crecimiento endotelio vascular) que inhibía la maduración de DC y que más bien incrementaba la proliferación de sus precursores CD34+ ${ }^{+16-18)}$.

Estudios in vivo también han demostrado en pacientes con cáncer de mama que la subpoblación de DC mieloides (DCm) estaba marcadamente disminuida $\mathrm{y}$, además, producian una reducida cantidad de IL12; sin embargo, estas alteraciones fueron revertidas por la resección quirdel tumor. En este caso, el factor soluble liberado por el tumor, que tuvo una correlación inversa con la cantidad de DCm, fue espermina, la que mostraba niveles séricos elevados ${ }^{(18)}$. Estudios in vitro utilizando el sobredanante de cultivo de líneas celulares cancerígenas y enfrentado a DC aisladas a partir de células mononucleares de sangre periférica (PBMC) también demostraron deficiencias en la maduración, pobre capacidad coestimuladora y de producción de IL12 llevando a las DC a la muerte por apoptosis ${ }^{(19)}$.

De tal manera que con evidencias como las anteriores resulta interesante la estrategía de la generación de una vacuna de DC producida in vitro y reinoculada al mismo sujeto para evitar los mecanismos de escape inmune que muestran los tumores y que burlan la inmunovigilancia ${ }^{(13,20)}$

\section{INMUNOTERAPIA CONTRA EL CÁNCER}

Con base en el conocimiento del funcionamiento y rol de las DC, en especial en la defensa contra células malignas, se han generado varios prospectos de vacunas celulares, principalmente en modelos murinos y menos en humanos, cuya finalidad es introducir antígenos tumorales ex vivo a las DC, mayormente obtenidas a partir de sangre periférica o médula ósea. 


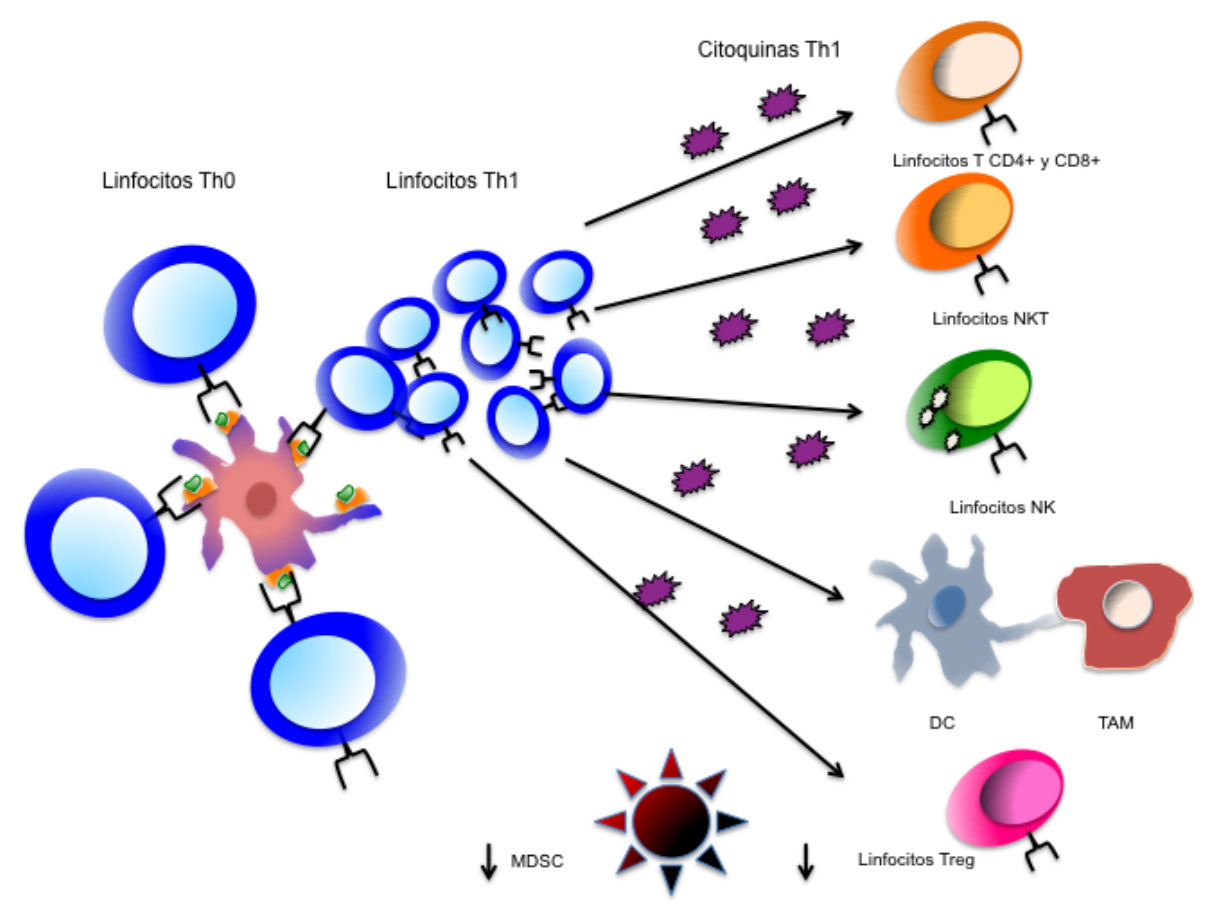

Figura 2. Vacuna de células dendríticas. Las DC autólogas cargadas in vitro con antígenos provenientes del tumor e inoculadas al mismo sujeto del cual se obtuvieron inducirán una respuesta Th1 caracterizada por la producción de citoquinas Th1 (Por ej. IFN-g y IL-2) que estimularán a poblaciones inmunocompetentes. Se espera que este tipo de inmunoterapia no incremente el número de LTreg y MDSC/TAM. DC (células dendríticas); IFN- $\gamma$ (interferon tipo gamma); LTreg (Linfocitos T reguladores); MDSC (células supresoras de origen mieloide). TAM (macrófagos infiltrantes de tumores)

Posteriormente, la estrategia ha sido inocular al mismo sujeto del cual se obtuvieron las DC con la vacuna celular esperando que se pueda estimular a los LT y otras células inmunocompetentes antitumorales ${ }^{(8,21,22)}$ (Figura 2). Existen variantes de las vacunas de DC, como por ejemplo, la presentación cruzada (MHC-I y II) de DC cargadas con antígenos provenientes del lisado tumoral y del ARN mensajero del tumor ${ }^{(23)}$, la cotransducción de estas DC con genes de antígenos tumorales o citoquinas como la IL-12 ${ }^{(24-26)}$ o ARN mensajero derivado del tumor completo ${ }^{(27,28)}$, generación de hibridomas por fusión entre células leucémicas y DC ${ }^{(29,30)}$ y la pulsación o carga de las $D C$ con péptidos antigénicos ${ }^{(22,31)} \mathrm{O}$ lisados del tumor maligno ${ }^{(22,29)}$, o tejidos premalignos ${ }^{(21)}$, células apoptóticas y necróticas o antígenos revestidos con anticuerpos para que las DC puedan reconocerlas vía sus receptores $\mathrm{Fc}^{(32)}$.

Aunque las vacunas de ADN son más estables que las de ARN, las primeras tienen la desventaja que podrían generar la inactivación de otros genes celulares, oncogénesis y la prolongada expresión de antígenos tumorales ${ }^{27,33)}$. También se han intentado tratamientos combinados de quimioterapia (Paclitaxel, una droga que bloquea el ciclo celular) a dosis bajas, y la inyección intratumoral de DC, lográndose en modelos murinos de fibrosarcoma la regresión del tumor. Sin embargo, el hecho de no generar DC inmaduras in vitro puede ser la causa de bajos niveles de protección ya que como células inmaduras las DC tienen una alta capacidad de ingesta de antígenos (34). Otras inmunoterapias combinadas utilizan vacunas de DC y anticuerpos contra moléculas agonistas como 4-1BB, importante para la activación de LT; sin embargo, se debe tener cuidado con las dosis del anticuerpo, porque pueden ser inmunosupresoras ${ }^{(35)}$. También se ha ensayado el bloqueo de moléculas inhibidoras de los LT con el uso combinado de anticuerpos anti-CTLA-4 y anti-PD-1 en pacientes con melanoma avanzado o metastásico lográndose respuestas exitosas ${ }^{(36)}$.

Se han diseñado varios ensayos clínicos para evaluar la seguridad y eficacia de las vacunas celulares con DC y se estima que hay muchas vacunas celulares en estudio (27,37); sin embargo, a la fecha, la respuesta obtenida no ha sido muy satisfactoria. La única vacuna celular autóloga (Sipuleucel-T) que ha sido aprobada por la FDA de los Estados Unidos muestra una sobrevida de 4,3 meses. Esta vacuna es elaborada a partir de PBMC de pacientes con cáncer de próstata, las que fueron tratadas con una proteína recombinante de fusión humana (PAP-GM-CSF, fosfatasa ácida 
prostática unida a factor estimulante de colonias de granulocitos-macrófagos) antes de la reinfusión. En este caso, se debe tener en cuenta que no solo están inlcuidas las DC como APC sino que también se encuentran linfocitos B (LB), LT (CD4 y CD8) y Natural Killer (NK) por lo que se podría generar una respuesta antitumoral policlonal ${ }^{(38)}$. Esta misma vacuna celular, en combinación con drogas anticancerígenas como abiraterona y/o prednisona, se encuentra en estudios de fase II, pero sin cambios significativos respecto al uso individual de la vacuna celular ${ }^{(39)}$. Otras estrategias de sinergía aplicadas en pacientes con cáncer de pulmón que resistieron una primera línea de quimioterapia con platino y una segunda con paclitaxel o carboplatino y que fueron vacunados con DC cargadas también han sido evaluadas $\sin$ resultados demasiado alentadores ${ }^{(40)}$.

A pesar de estas estrategías la efectividad terapeútica de las vacunas de $\mathrm{DC}$ no ha sido satisfactoria, probablemente porque muchas de las condiciones fisiológicas a las que están sometidas no son reproducidas in vitro. Por ejemplo, es importante el estado de madurez de las DC, ya que en el estadio inmaduro tienen una alta capacidad de captura y procesamiento de antígenos, mientras que una vez maduras cambian esta capacidad por otra caracterizada por un alto grado de activación orientado a la presentación de antígenos a los LT ${ }^{(41,42)}$. Cuando se diseña una vacuna de DC se debe conocer a profundidad la inmunobiología de las DC para imitar artificialmente el proceso fisiológico natural de estas células, porque, paradojicamente, su uso en el tratamiento del cáncer también podría ser responsable de la inducción de enfermedades autoinmunes y mediadas por patógenos, reacciones alérgicas, rechazo de injertos y fallas del sistema inmune ${ }^{(43)}$. Por este motivo, algunos protocolos intentan utilizar DC maduras "jovenes" generadas en 3 días de cultivo que DC maduras "viejas" utilizadas después de 7 días de cultivo; esto permitiría mejorar la primera señal de presentación de antígeno, la segunda señal coestimuladora y la tercera señal de producción de citoquinas inductoras de una respuesta antitumoral Th1/Tc1 ${ }^{(44)}$.

Van Gundy ZC et al., recientemente, han demostrado que el cáncer de mama metastásico incrementa su progresión debido a la existencia de células supresoras de origen mieloide [myeloid derived suppressor cells (MDSC)] ${ }^{(45)}$. Estas MDSC (CD11 b+Gr-1+MHC-I+MHC$\left.\mathrm{II}^{-}\right)$, presentes en humanos y en ratones, inicialmente fueron conocidas como células mieloides inmaduras (iMC) . Son un grupo complejo de células conformado por células mieloides maduras (granulocitos, monocitos/ macrófagos y DC) y precursores mielomonociticos inmaduros; las MSDC tienen relación con los TAM (macrófagos infiltrantes de tumores) pudiéndose diferenciar en ellos; su migración al microambiente tumoral se produce debido a citoquinas, quimioquinas, factores de crecimiento y compuestos biológicamente activos ${ }^{(48,49)}$. Una de sus funciones es participar en la neoangiogénesis y en el sostenimiento del crecimiento tumoral, alterando la función de células inmunes, como se demostró experimentalmente cuando se inyectaron células tumorales subcutaneamente en la almohadilla mamaria de ratones, observándose un incremento en la cantidad de MDSC y una disminución de la proliferación celular. Especificamente, su actividad inmunosupresora se da a través del metabolismo de la L-arginina y la acción de las enzimas iNOS (oxido nitritico sintetasa inducible) y NOS2 que producen NO y Arginasa 1. La presencia de arginasa disminuye la expresión de CD3 importante para la señalización de LT y lo detiene en la fase celular Go-G1; el NO altera las vías de activación del LT por el receptor de IL-2 (IL-2R) y la presencia de L-arginina en el microambiente tumoral puede generar especies reactivas del oxígeno (ROS) como el superóxido $\left(\mathrm{O}_{2}^{-}\right)$ que al interactuar con NO generan a su vez especies reactivas del nitrógeno (RNS) como los peroxinitritos que pueden alterar la señalización intracelular e inducir apoptosis de LT (16,45,48,49). Particularmente las MSDC afectan a la subpoblación de $\mathrm{LT} C D 8^{+}$más no a los $\mathrm{LT}$ $\mathrm{CD}^{+}{ }^{(48)}$.

Por tanto, las actuales inmunoterapías deberían considerar la eliminación o medición del efecto de las MDSC como una estrategia de mejora ${ }^{(41)}$. Existen drogas que fuerzan la diferenciación, inhiben la maduración, reducen la acumulación en órganos periféricos y afectan las funciones de MDSC; una de las más eficientes es $\operatorname{ATRA}($ All trans-Retinoic Acid), un derivado de la vitamina $A$, que junto con el factor estimulante de colonias de granulocito-macrófago (GM-CSF) logran diferenciar las MDSC de ratones portadores de tumor hacia DCm; ATRA no reduce el tumor sino favorece la defensa inmune dirigida por DC, macrófagos y granulocitos ${ }^{(49)}$.

Dentro de las inmunoterapias más conocidas para melanoma se encuentran el interferon-a2 $\beta$ (IFNa2 $\beta$ ) (Intron A; Schering Corporation, Kenilworth, NJ) y la interleuquina-2 (IL-2) (Aldesleukin, Proleukin; Novartis Vaccines and Diagnostics Inc, Emeryville, CA) aprobadas por la FDA en 1995 y 1998, respectivamente. Los interferones tipo I (IFN- $\alpha$ ) son citoquinas altamente pleiotrópicas con propiedades inmunorreguladoras, antiproliferativas, inductoras de diferenciación, apoptóticas y antiangiogénicas en múltiples cánceres; mientras que IL-2 tiene un rol importante en la regulación immune y proliferación de linfocitos T. Dosis altas de IL-2 intravenosa demostraron efectos antitumorales en ocho ensayos clínicos realizados entre 1985 y 1993 en 270 pacientes con melanoma metastásico avanzado. Aun así, en el tratamiento con IFN existen problemas de tolerabilidad como síntomas parecidos a la gripe, 
anorexia, fatiga y depresión, mientras que en el caso de IL-2 se han identificado problemas de autoinmunidad y disfunción tiroidea que no han sido del todo esclarecidos; aun así, se concluye que la autoinmunidad es un signo de la ruptura de la tolerancia tumoral y se asocia con una mayor supervivencia ${ }^{(12)}$, aunque algunos discuten la aparición de enfermedades como el vitiligo en pacientes tratados con vacunas de DC cargadas con antígenos de melanoma ${ }^{(50)}$

En melanoma también se han aprovechado los mecanismos naturales para frenar la activación exagerada de los LT, en una respuesta immune convencional, a favor de generar una respuesta antitumoral masiva, tal es el caso de la molécula CTLA4 (Cytotoxic T Lymphocyte-associated Antigen 4) que al ser bloqueada por anticuerpos monoclonales se evita que se una a las moléculas coestimuladoras B7; no se enviarán señales negativas a los LT y estos podrán proliferar y activarse para participar en la respuesta antitumoral. El Tremelimumab (CP-675,206; Pfizer Inc) y el Ipilimumab (MDX-010; Medarex Inc/Bristol-Myers Squibb) son dos anticuerpos totalmente humanizados anti-CTLA-4 para el tratamiento de melanoma. En ambos casos se evaluaron en ensayos clínicos distintas dosis y tiempos de tratamiento, obteniéndose en el caso de Tremelimumab que de 29 y 89 pacientes con distintos esquemas, solo 2 y 3 pacientes, respectivamente, tuvieron respuesta completa; mientras que en el caso de Ipilimumab, de 36 y 56 pacientes también con distintos esquemas de tratamiento solo 3 y 2 pacientes, respectivamente, tuvieron respuesta completa $\mathrm{y}$, en ambos casos, se encontraron efectos adversos como diarrea, dermatitis, prurito, fatiga, colitis e hipofisitis (12). En el caso de el tratamiento de melanomas humanos, recientemente la FDA aprobó el uso de Keytruda ${ }^{\circledR}$ (pembrolizumab) (Merck, USA) solo con un estudio en fase I. Keytruda ${ }^{\circledR}$ un anticuerpo monoclonal humanizado contra PD-1 (programmed death receptor - 1), la molécula inhibidora de la activación de los LT regulada por el melanoma, ha demostrado un reducción en el $24 \%$ de pacientes incluidos en el estudio y con un efecto que puede durar entre 1,5 a 8,5 meses ${ }^{(51)}$. El uso de agonistas de TLR-9 también ha sido evaluado en el melanoma, en este caso los agonistas simulan la capacidad de TLR-9 de reconocer una secuencia no metilada de citocina-guanina $(\mathrm{CpG})$ para inducir la maduración y mejorar la presentación de antígenos por las DC. El agonista evaluado es PF-3512676 o CPG7909, se administró a 20 pacientes con melanoma en estadios IIIB/C y IV y se obtuvieron respuestas parciales solo en dos pacientes, y alcanzaron respuestas estables tres pacientes a quienes se les encontró regresión metastásica y leves efectos adversos de síntomas similares a la gripe ${ }^{(12)}$. El Canvaxin (Cancer Vax Corp) es una vacuna celular de melanoma que expresa cerca de veinte antígenos tumorales que ha demostrado menos de $5 \%$ de sobrevivencia de pacientes con melanoma en estadios III y IV generando, posiblemente, problemas de inmunosupresión de relevancia clínica.

La clonación de anígenos asociados a melanoma o antígenos de línea germinal cancerígena de melanoma (por ej. MAGE-1,-3 entre otros) han generado la elaboración de vacunas péptidicas o proteícas, y muchos han sido evaluados en estudios clínicos de fase II como vacunas péptidicas, multiepitópicas o proteícas. Las vacunas péptidicas asociadas con adjuvante incompleto de Freund han sido poco inmunogénicas y no produjeron una respuesta inmune robusta ${ }^{(37)}$. Es posible que esta baja inmunogenicidad esté asociada a la rápida digestión proteolítica de los péptidos y, en los casos en que se estimuló a los LT citotóxicos, estos no eran funcionalmente eficientes ${ }^{(50)}$. En estudios aleatorios de fase III, comparados con quimioterapia, las vacunas celulares Allovectin-7 (Vical Inc, San Diego, CA), Canvaxin y Melacine (Corixa Corp, Seattle, WA) fallaron en mejorar la respuesta inmune y la sobrevivencia de los pacientes ${ }^{(12)}$. Debido a estas experiencias previas se recomienda, además de la rigurosidad en la definición de los antígenos péptidicos, la incorporación del laboratorio como parte de la evaluación de la respuesta al tratamiento, lo que permitirá que mediante técnicas como ELISPOT y citometría de flujo, se pueda detectar la frecuencia de células efectoras específicas a tumores funcionales con una sensibilidad adecuada que permita el análisis en los ensayos de vacunas ${ }^{(12)}$. Nestlé et al., evaluaron en 16 pacientes con melanoma metastásico, vacunas de DC cargadas con HLA-A2/tirosinasa, gp100, péptidos de melan-A, péptidos MAGE-A1/MAGEA-3 asociados a HLA-A1 y lisados tumorales. Las DC se inyectaron mensualmente hasta un máximo de diez inyecciones. Se encontraron respuestas objetivas en 5 de 16 pacientes y respuestas completas solo en dos pacientes; sin embargo, once pacientes desarrollaron hipersensibilidad de tipo retardado. También se han vacunado pacientes con el haplotipo HLA-A1 y con melanoma metastásico que expresaban MAGE-A3 con cinco vacunas de DC cargadas con péptidos MAGE-A3 encontrándose considerables cantidades de linfocitos $\mathrm{T}$ citotóxicos (LTC) específicos para este péptido en ocho de once pacientes; sin embargo, se observaron regresiones de metastasis en seis de once pacientes ${ }^{\left({ }^{37}\right)}$.

Desde el punto de vista clínico, la respuesta inmune celular contra el melanoma tiene el mayor potencial pronóstico y significancia predictiva. Los infiltrados de LT en el melanoma primario son pronóstico de la evolución de la enfermedad; sin embargo, uno de los mecanismos más importantes del escape inmune en melanoma es la "desregulación" de los componentes de la maquinaria de presentación de antígenos, sobre 
todo en la vía del MHC I como la $\beta 2$ microglobulina, TAP-1/TAP-2 y péptidos transportadores. Asimismo, los tumores no solo liberan citoquinas inmunosupresoras, sino también son capaces de inducir en las células inmunes que los rodean, la liberación de estas citoquinas inmunosupresoras como la $\mathrm{IL}-10$ y el TGF- $\beta$; mientras que la IL-10 inhibe la presentación de antígenos y la proliferación de LT específicos, el TGF- $\beta$ inhibe la activación y proliferación celular ${ }^{(52,53)}$. Por tanto, la "desregulación" causada por factores inmunosupresores también es una condición que considerar en el desarrollo de nuevas inmunoterapias contra melanoma ${ }^{(27)}$

\section{DIFERENCIACIÓN IN VITRO DE CÉLULAS DENDRITTICAS}

Existen muchos protocolos que permiten obtener DC a partir de progenitores provenientes de distintas fuentes como médula ósea, sangre de cordón, sangre periférica y bazo de ratones. En 1992 se describió por primera vez el primer protocolo para expandir precursores hematopoyéticos derivados de médula ósea, utilizando GM-CSF en ratas, luego en ratones y finalmente en humanos ${ }^{(53)}$. Siendo la fuente de tejido celular el criterio más importante que tener en cuenta para la generación de DC, la médula ósea y el bazo en ratones y los monocitos de sangre periférica en humanos son las fuentes de tejido preferidas; sin embargo, como existen precursores hematopoyéticos $\mathrm{CD} 34^{+}$en otros tejidos, estos también podrían usarse ${ }^{(17)}$. Los factores de crecimiento son esenciales para el desarrollo y diferenciación de las DC, por lo que, convencionalmente, se utiliza GM-CSF o IL-3, aunque se debe considerar que se pueden cogenerar neutrófilos (GM-CSF) y mastocitos (IL-3), mientras que cuando se utiliza Flt3-L se puede generar una mezcla de DC convencionales y DC plasmacitoides (DCp). Otro criterio es la dosis de GM-CSF ya que se pueden obtener DC maduras a dosis mayores a $200 \mathrm{U} / \mathrm{mL}$, mientras que dosis bajas conducen a DC inmaduras tolerogénicas y resistentes a la maduración ${ }^{(17)}$. La mayoría de protocolos, además, acompañan los cultivos con cofactores como IL-4, que en ratones y humanos permite la maduración de DC cuando hay una disminución de GM-CSF, debido a que este factor tiene una corta vida media en los cultivos (17,54); TNF- $\alpha$ (factor de necrosis tumoral tipo alfa) que en ratones y humanos genera células de Langerhans epidermales y otras muy parecidas a DC derivadas de monocitos y células dermales ${ }^{(55)}$, o IL-7 que en humanos comparte con IL-4 una unidad común del receptor gamma y la vía de señalización de la Jak-3 kinasa, por lo que es importante en la mielopoyesis temprana ${ }^{(34)}$. También es posible combinar GM-CSF con CD40L/gp39 o ligando de c-kit ${ }^{(54)}$

\section{EFECTOS INMUNOMODULADORES DE PLANTAS MEDICINALES SOBRE CÉLULAS DENDRIITICAS}

Es sabido que las plantas medicinales tienen propiedades antitumorales, muchas de las cuales han sido demostradas científicamente y van desde actividades enzimáticas, antiangiogénicas, reparadoras del ADN hasta inhibidoras del crecimiento tumoral y recobradoras de poblaciones neutrofilicas después de una quimioterapia, por lo que no es de extrañar que algunas de estas plantas hayan sido evaluadas de manera especifica con las DC ${ }^{(57-62)}$. A pesar de las múltiples estrategias en el uso de DC como vacunas celulares contra tumores, muchas de ellas han mostrado fallas en la presentación de antígenos y la inducción de anergía a LT. Los estudios que han evaluado las propiedades inmunomoduladoras de las plantas medicinales sobre DC demuestran que tienen efectos inhibidores de la maduración de las DC, como el caso de curcumina, un extracto de Curcuma longa, que a través de la inhibición de la vía NFאB dirige la diferenciación de DC a células tolerogénicas, esta propiedad podría ser evaluada si se considera que para cargar con un antígeno a una DC esta lo hará de manera eficiente, si se encuentra en un estadio inmaduro ${ }^{(55)}$. Fukui et al., evaluaron 99 plantas de la medicina tradicional China; los ensayos de citotoxicidad realizados sobre una línea celular de DC (XS106) demostraron que a $10 \mathrm{ug} / \mathrm{mL}$ ninguno de los extractos era citotóxico, sin embargo, solo el extracto de Amomi semen (una semilla de Amomun xanthioides, Zingiberaceae) demostró incrementar la expresión de MHC II, CD80, CD86 y la produción de IL-12 p70 no solo en DC (XS106), sino también en DC generadas a partir de médula ósea de ratones; adicionalmente, estas células demostraron un incremento en la producción de IFN- $\gamma$ por LT cuando se realizaron cocultivos. Finalmente, en un modelo animal tumoral las DC tratadas con Amomi semen produjeron un $60 \%$ de sobrevivencia de los ratones ${ }^{(56)}$. Nuestro grupo, utilizando un extracto hidroalcohólico de Uncaria tomentosa (uña de gato), conocido por poseer propiedades antiinflamatorias, antioxidantes y antitumorales (58,63-65), demostró que, además, tenía un efecto inmunomodulador sobre las $\mathrm{DCm}$ provenientes de PBMC de pacientes con artritis reumatoide, disminuyendo la expresión de CD11c, pero incrementado la expresión de HLA-DR y CD86 de manera dosis-dependiente ${ }^{(66)}$; similares resultados encontramos con DCm provenientes de PBMC de sujetos sanos, donde el extracto de uña de gato disminuía la expresión de CD11c, pero no modificaba la expresión de HLA-DR y CD86 ${ }^{(67)}$.

El ácido uncarínico (URC) es un triterpeno aislado de Uncaria rhynchophylla con diversas actividades biológicas, una de ellas es el mejoramiento de la 
expresión de molecúlas de maduración (HLA-DR) y activación (CD80, CD83, CD86, CD40, CD54) de DC humanas tratadas con este compuesto. EI URC a 0,1uM incrementó significativamente la producción de IL-12p70 a través del receptor TLR4 (Toll-like Receptor 4) y de la translocación del NFKB al núcleo, cuando estas DC fueron enfrentadas a LT incrementaron la producción de IFN- $\gamma$ ejerciendo un direccionamiento Th1. Por otro lado, también se mejoró la actividad de los LT CD8 ${ }^{+}$cuando estos se enfrentaron a líneas celulares tumorales, induciendo en estas últimas la muerte por apoptosis ${ }^{(68)}$. Un extracto hidroalcohólico de Uncaria rhynchophylla, rico en ácido uncarinico $C$ y $D(0,01-0,1 \mathrm{mM})$, mejoró la expresión de CD1a, CD80, CD83, CD86 y HLA-DR en DC de origen humano ${ }^{(69,70)}$.

Dadas las evidencias anteriores sobre algunos productos naturales es válida la idea de ensayarlos con DC que vayan a ser utilizadas como vacunas celulares, en vista de que podrían mejorar su capacidad de presentación de antígenos y de indución de respuestas antitumorales.

\section{CONCLUSIONES}

A pesar de que los avances en melanoma han llegado a encontrar potenciales genes blanco terapeúticos para su uso en vacunas celulares ${ }^{(71)}$, se debe tener en cuenta que la biología de los tumores puede ser sumamente compleja como para restringirse a este grupo de genes, por lo que creemos que todas las estrategias o combinaciones deben ser ensayadas en busca de un potenciamiento del sistema inmune del individuo con melanoma u otro tipo de cáncer. Asimismo, creemos que el conocimiento profundo de los mecanismos básicos del sistema inmune nos darán vías cada vez más específicas y menos citotóxicas en el tratamiento. El uso de vacunas celulares con DC para melanoma es una excelente estrategía que debe mejorarse con adyuvantes (por ej. biosimilares) que induzcan una mejor actividad de presentación de antígenos y activación de poblaciones inmunocompetentes. Finalmente, la eliminación y/o evaluación del efecto de las MDSC o de los TAM durante el desarrollo de una vacuna celular o durante su aplicación debe ser tenida en cuenta para garantizar la efectividad de la vacuna celular.

Contribuciones de autoría: ILR ha participado en la concepción y diseño del artículo, recolección y obtención de resultados, análisis e interpretación de datos, ademas junto con CN y JLA han participado en la redacción del artículo, revisión crítica del artículo y aprobación de su versión final.

Fuentes de financiamiento: autofinanciado.

Conflictos de interés: los autores declaran no tener conflictos de interés.

\section{REFERENCIAS BIBLIOGRÁFICAS}

1. Steinman RM, Cohn ZA. Identification of a novel cell type in peripheral lymphoid organs of mice. I. Morphology, quantitation, tissue distribution. J Exp Med. 1973;137(5):1142-62.

2. Steinman RM, Witmer MD. Lymphoid dendritic cells are potent stimulators of the primary mixed leukocyte reaction in mice. Proc Natl Acad Sci U S A. 1978;75(10):5132-6.

3. Janeway C, Travers P, Walport M, Shlomichick M. Immunobiology. 6th ed. New York: Garland Publishing; 2005.

4. Celia M, Sallusto F, Lanzavecchia A. Origin, maturation and antigen presenting function of dendritic cells. Curr Opin Immunol. 1997;9:10-6.

5. Liu K, Waskow C, Liu X, Yao K, Hoh J, Nussenzweig M. Origin of dendritic cells in peripheral lymphoid organs of mice. Nat Immunol. 2007;8(6):578-83.

6. Lutz MB, Schuler G. Immature, semimature and fully mature dendritic cells: which signals induce tolerance or immunity?. Trends Immunol. 2002;23(9):445-9.

7. Banchereau J, Briere F, Caux C, Davoust J, Lebecque S, Liu YJ, et al. Immunobiology of dendritic cells. Annu Rev Immunol. 2000;18:767-811.

8. Asada H, Kishida T, Hirai H, ShinYa M, Imanishi J, Takeuchi M, et al. Combination vaccine of dendritic cells (DCs) and T cells effectively suppressed preestablished malignant melanoma in mice. Cancer Lett. 2006;240(1):83-93.

9. Creusot RJ, Mitchison NA. How DCs control cross-regulation between lymphocytes. Trends Immunol. 2004;25(3):126-31.
10. Steinman RM, Hawiger D, Nussenzweig MC. Tolerogenic dendritic cells. Annu Rev Immunol. 2003;21:685-711.

11. Guindi C, Ménard M, Cloutier A, Gaudreau S, Besin G, Larivée $P$, et al. Differential role of NF- $\kappa$, ERK1/2 and AP-1 in modulating the immunoregulatory functions of bone marrow-derived dendritic cells from NOD mice. Cell Immunol. 2012;272(2):259-68. doi: 10.1016/j. cellimm.2011.10.005.

12. Kirkwood JM, Tarhini AA, Panelli MC, Moschos SJ, Zarour HM, Butterfield LH, et al. Next generation of immunotherapy for melanoma. J Clin Oncol. 2008;26(20):3445-55. doi: 10.1200/JCO.2007.14.6423.

13. Dunn GP, Old LJ, Schreiber RD. The immunobiology of cancer immunosurveillance 
and immunoediting. Immunity. 2004;21(2):137-48.

14. Reiman JM, Kmieciak M, Manjili MH, Knutson KL. Tumor immunoediting and immunosculpting pathways to cancer progression. Semin Cancer Biol. 2007;17(4):275-87.

15. Koebel CM, Vermi W, Swann JB, Zerafa N, Rodig SJ, Old LJ, et al. Adaptive immunity maintains occult cancer in an equilibrium state. Nature. 2007;450(7171):903-7.

16. Gabrilovich D. Mechanisms and functional significance of tumourinduced dendritic-cell defects. Nat Rev Immunol. 2004;4(12):941-52.

17. Howard CJ, Hope JC. Dendritic cells, implications on function from studies of the afferent lymph veiled cell. Vet Immunol Immunopathol. 2000;77(1-2):1-13.

18. Della Bella $S$, Gennaro M, Vaccari M, Ferraris C, Nicola S, Riva A, et al. Altered maturation of peripheral blood dendritic cells in patients with breast cancer. $\mathrm{Br} \mathrm{J}$ Cancer. 2003;89(8):1463-72.

19. Kiertscher SM, Luo J, Dubinett SM, Roth MD. Tumors promote altered maturation and early apoptosis of monocyte-derived dendritic cells. J Immunol. 2000;164(3):1269-76.

20. Dunn GP, Bruce AT, Ikeda $\mathrm{H}$, Old LJ, Schreiber RD. Cancer immunoediting: from immunosurveillance to tumor escape. Nat Immunol. 2002;3(11):991-8.

21. De Costa AM, Justis DN, Schuyler C, Young MR. Administration of a vaccine composed of dendritic cells pulsed with premalignant oral lesion lysate to mice bearing carcinogeninduced premalignant oral lesions stimulates a protective immune response. Int Immunopharmacol. 2012;13(3):322-30. doi: 10.1016/j. intimp.2012.05.004.

22. Takahashi H,Okamoto M,Shimodaira S, Tsujitani S, Nagaya M, Ishidao T, et al. Impact of dendritic cell vaccines pulsed with Wilms' tumour-1 peptide antigen on the survival of patients with advanced non-small cell lung cancers. Eur J Cancer. 2013;49(4):852-9. doi: 10.1016/j.ejca.2012.11.005.

23. Decker WK, Xing D, Li S, Robinson SN, Yang H, Yao X, et al. Double loading of dendritic cell MHC class I and MHC class II with an AML antigen repertoire enhances correlates of $\mathrm{T}$-cell immunity in vitro via amplification of $\mathrm{T}$-cell help. Vaccine. 2006;24(16):3203-16.

24. Okada N, Liyama S, Okada Y, Mizuguchi $\mathrm{H}$, Hayakawa $\mathrm{T}$, Nakagawa S, et al. Immunological properties and vaccine efficacy of murine dendritic cells simultaneously expressing melanoma-associated antigen and interleukin-12. Cancer Gene Ther. 2005;12(1):72-83.

25. Zhang S, Zeng G, Wilkes DS, Reed GE, McGarry RC, Eble JN, et al. Dendritic cells transfected with interleukin-12 and pulsed with tumor extract inhibit growth of murine prostatic carcinoma in vivo. Prostate. 2003;55(4):292-8.

26. Zhang S, Li W, Xia Z, Mao Y. CD4 $T$ cell dependent tumor immunity stimulated by dendritic cell based vaccine. Biochem Biophys Res Commun. 2011;413(2):294-8. doi: 10.1016/j.bbrc.2011.08.089.

27. Kyte JA, Mu L, Aamdal S, Kvalheim G, Dueland S, Hauser M, et al. Phase I/II trial of melanoma therapy with dendritic cells transfected with autologous tumor-mRNA. Cancer Gene Ther. 2006;13(10):905-18.

28. Garg NK, Dwivedi P, Prabha P, Tyagi RK. RNA pulsed dendritic cells: an approach for cancer immunotherapy. Vaccine. 2013;31(8):1141-56. doi: 10.1016/j.vaccine.2012.12.027.

29. Galea-Lauri J, Darling D, Mufti G, Harrison P, Farzaneh F. Eliciting cytotoxic $\mathrm{T}$ lymphocytes against acute myeloid leukemia-derived antigens: evaluation of dendritic cell-leukemia cell hybrids and other antigen-loading strategies for dendritic cell-based vaccination. Cancer Immunol Immunother. 2002;51(6):299-310.

30. Yasuda T, Kamigaki T, Nakamura T, Imanishi T, Hayashi S, Kawasaki K, et al. Dendritic cell-tumor cell hybrids enhance the induction of cytotoxic T lymphocytes against murine colon cancer: A comparative analysis of antigen loading methods for the vaccination of immunotherapeutic dendritic cells. Oncol Rep. 2006;16(6):1317-24.

31. Dissanayake D, Murakami K, Tran MD, Elford AR, Millar DG, Ohashi
PS. Peptide-pulsed dendritic cells have superior ability to induce immune-mediated tissue destruction compared to peptide with adjuvant. PLoS One. 2014;9(3):e92380. doi: 10.1371/journal.pone.0092380.

32. Campisano S, Mac Keon S, Gazzaniga S, Ruiz MS, Traian MD, Mordoh J, et al. Anti-melanoma vaccinal capacity of CD11c-positive and -negative cell populations present in GMCSF cultures derived from murine bone marrow precursors. Vaccine. 2013;31(2):354-61. doi: 10.1016/j. vaccine.2012.10.114.

33. O’Neill DW, Adams S, Bhardwaj N. Manipulating dendritic cell biology for the active immunotherapy of cancer. Blood. 2004;104(8):2235-46.

34. Choi GS, Lee MH, Kim SK, Kim CS, Lee HS, Im MW, et al. Combined treatment of an intratumoral injection of dendritic cells and systemic chemotherapy (Paclitaxel) for murine fibrosarcoma. Yonsei Med J. 2005;46(6):835-42.

35. Lee H, Park HJ, Sohn HJ, Kim JM, Kim SJ. Combinatorial therapy for liver metastatic colon cancer: dendritic cell vaccine and lowdose agonistic anti-4-1BB antibody co-stimulatory signal. J Surg Res. 2011;169(1):e43-50. doi: 10.1016/j. jss.2011.03.067.

36. Raval RR, Sharabi AB, Walker AJ, Drake CG, Sharma P. Tumor immunology and cancer immunotherapy: summary of the 2013 SITC primer. J Immunother Cancer. 2014;2:14. doi: 10.1186/2051-1426-2-14.

37. Smith C, Cerundolo V. Immunotherapy of melanoma. Immunology. 2001;104(1):1-7.

38. Sims RB. Development of sipuleucel-T: autologous cellular immunotherapy for the treatment of metastatic castrate resistant prostate cancer. Vaccine. 2012;30(29):4394-7. doi: 10.1016/j.vaccine.2011.11.058.

39. Singh BH, Gulley JL. Therapeutic vaccines as a promising treatment modality against prostate cancer: rationale and recent advances. Ther Adv Vaccines. 2014;2(5):137-48. doi: $10.1177 / 2051013614539478$.

40. Zitvogel L, Apetoh L, Ghiringhelli F, Kroemer G. Immunological aspects 
of cancer chemotherapy. Nat Rev Immunol. 2008;8(1):59-73.

41. Lipscomb MF, Masten BJ. Dendritic cells: immune regulators in health and disease. Physiol Rev. 2002;82(1):97-130.

42. Menges M, Rössner S, Voigtländer C, Schindler $\mathrm{H}$, Kukutsch NA, Bogdan C, et al. Repetitive injections of dendritic cells matured with tumor necrosis factor alpha induce antigen-specific protection of mice from autoimmunity. J Exp Med. 2002;195(1):15-21.

43. Ardavín C, Amigorena S, Reis e Sousa C. Dendritic cells: immunobiology and cancer immunotherapy. Immunity. 2004;20(1):17-23.

44. Frankenberger B, Schendel DJ. Third generation dendritic cell vaccines for tumor immunotherapy. Eur J Cell Biol. 2012;91(1):53-8. doi: 10.1016/j.ejcb.2011.01.012.

45. Vangundy ZC, Markowitz J, Baker JD, Strange HR, Papenfuss TL. An In vitro Model System to Generate Breast Cancer MDSCs and Study Immune Cell Interactions in Immunocompetent C57bl / 6 Mice. J Cancer Biol Res. 2014;2(1):2-6.

46. Zhou Z, French DL, Ma G, Eisenstein S, Chen Y, Divino CM, et al. Development and function of myeloid-derived suppressor cells generated from mouse embryonic and hematopoietic stem cells. Stem Cells. 2010;28(3):620-32. doi: $10.1002 /$ stem.301.

47. Kotsakis A, Harasymczuk M, Schilling B, Georgoulias V, Argiris A, Whiteside TL. Myeloid-derived suppressor cell measurements in fresh and cryopreserved blood samples. J Immunol Methods. 2012;381(12):14-22. doi: $10.1016 / \mathrm{j}$. jim.2012.04.004.

48. Ugel S, Delpozzo F, Desantis G, Papalini F, Simonato F, Sonda N, et al. Therapeutic targeting of myeloidderived suppressor cells. Curr Opin Pharmacol. 2009;9(4):470-81. doi: 10.1016/j.coph.2009.06.014.

49. Talmadge JE, Gabrilovich DI. History of myeloid-derived suppressor cells. Nat Rev Cancer. 2013;13(10):739-52. doi: 10.1038/ $\operatorname{nrc} 3581$.

50. Durrant LG, Scholefield JH. Principles of cancer treatment by immunotherapy. Surgery. 2006;24(2):55-8.

51. Pollack A. F.D.A. Allows first use of a novel cancer drug. The New York Times. 2014 Sept 4.

52. Lutz MB, Rössner S. Factors influencing the generation of murine dendritic cells from bone marrow: the special role of fetal calf serum. Immunobiology. 2007;212(910):855-62.

53. Seager Danciger J, Lutz M, Hama S, Cruz D, Castrillo A, Lazaro J, et al. Method for large scale isolation, culture and cryopreservation of human monocytes suitable for chemotaxis, cellular adhesion assays, macrophage and dendritic cell differentiation. J Immunol Methods. 2004;288(1-2):123-34.

54. Takahashi K, Honeyman MC, Harrison LC. Dendritic cells generated from human blood in granulocyte macrophage-colony stimulating factor and interleukin-7. Hum Immunol. 1997;55(2):103-16.

55. Rogers NM, Kireta S, Coates PT. Curcumin induces maturationarrested dendritic cells that expand regulatory $\mathrm{T}$ cells in vitro and in vivo. Clin Exp Immunol. 2010;162(3):460-73. doi: 10.1111/j.1365-2249.2010.04232.x.

56. Fukui H, Mitsui S, Harima N, Nose $\mathrm{M}$, Tsujimura K, Mizukami $\mathrm{H}$, et al. Novel functions of herbal medicines in dendritic cells: role of Amomi Semen in tumor immunity. Microbiol Immunol. 2007;51(11):1121-33.

57. Yang CS, Wang X, Lu G, Picinich SC. Cancer prevention by tea: animal studies, molecular mechanisms and human relevance. Nat Rev Cancer. 2009;9(6):429-39. doi: 10.1038/ nrc2641.

58. Dreifuss AA, Bastos-Pereira AL, Fabossi IA, Lívero FA, Stolf AM, Alves de Souza CE, et al. Uncaria tomentosa exerts extensive anti-neoplastic effects against the Walker-256 tumour by modulating oxidative stress and not by alkaloid activity. PLoS One. 2013;8(2):e54618. doi: 10.1371/ journal.pone.0054618.

59. Akesson C, Lindgren H, Pero RW, Leanderson T, Ivars F. An extract of Uncaria tomentosa inhibiting cell division and NF-kappa B activity without inducing cell death. Int Immunopharmacol. 2003;3(1314):1889-900.

60. Pilarski R, Filip B, Wietrzyk J, Kuras M, Gulewicz K. Anticancer activity of the Uncaria tomentosa (Willd.) DC. preparations with different oxindole alkaloid composition. Phytomedicine. 2010;17(14):1133-9. doi: 10.1016/j. phymed.2010.04.013.

61. Lo YC, Yang YC, Wu IC, Kuo FC, Liu CM, Wang HW, et al. Capsaicininduced cell death in a human gastric adenocarcinoma cell line. World J Gastroenterol. 2005;11(40):6254-7.

62. Farias I, do Carmo Araújo $M$, Zimmermann ES, Dalmora SL, Benedetti AL, Alvarez-Silva M, et al. Uncaria tomentosa stimulates the proliferation of myeloid progenitor cells. J Ethnopharmacol. 2011;137(1):856-63. doi: 10.1016/j. jep.2011.07.011.

63. Aguilar JL, Rojas P, Marcelo A, Plaza A, Bauer R, Reininger E, et al. Antiinflammatory activity of two different extracts of Uncaria tomentosa (Rubiaceae). J Ethnopharmacol. 2002 Jul;81(2):271-6.

64. Sandoval M, Okuhama NN, Zhang XJ, Condezo LA, Lao J, Angeles' $\mathrm{FM}$, et al. Anti-inflammatory and antioxidant activities of cat's claw (Uncaria tomentosa and Uncaria guianensis) are independent of their alkaloid content. Phytomedicine. 2002;9(4):325-37.

65. Miller MJ, Angeles FM, Reuter BK, Bobrowski P, Sandoval M. Dietary antioxidants protect gut epithelial cells from oxidant-induced apoptosis. BMC Complement Altern Med. 2001;1:11.

66. Nuñez C, Lozada-Requena I, Akamine I, Carbajal L, Aguilar JL. Efecto de Uncaria tomentosa (Uña de gato) sobre la población y activación de células dendríticas en sangre periférica de pacientes con artritis reumatoidea. Acta Med Per. 2008;25(3):135-9.

67. Lozada-Requena I, Núñez C, Álvarez Y, Aguilar JL. Efecto de un extracto hidroalcohólico de Uncaria tomentosa (uña de gato) sobre la población de células dendríticas y sus moléculas HLA-DR y CD86 ante el estimulo con lipopolisacáridos. 
Rev Peru Med Exp Salud Publica. 2009;26(2):168-74.

68. Bae WK, Umeyama A, Chung I-J, Lee JJ, Takei M. Uncarinic acid C plus IFN- $\gamma$ generates monocytederived dendritic cells and induces a potent Th1 polarization with capacity to migrate. Cell Immunol. 2010;266(1):104-10. doi: 10.1016/j. cellimm.2010.09.004

69. Kim KS, Pham TN, Jin CJ, Umeyama A, Shoji N, Hashimoto $\mathrm{T}$, et al. Uncarinic Acid C Isolated from Uncaria rhynchophylla
Induces Differentiation of Th1Promoting Dendritic Cells Through TLR4 Signaling. Biomark Insights. 2011;6:27-38. doi: 10.4137/BMI. S6441.

70. Umeyama A, Yahisa Y, Okada M, Okayama E, Uda A, Shoji N, et al. Triterpene esters from Uncaria rhynchophylla drive potent IL12-dependent Th1 polarization. J Nat Med. 2010;64(4):506-9. doi: 10.1007/s11418-010-0438-1.

71. National Cancer Institute. Seven potential immunotherapy targets for treatment of melanoma identified [Internet]. 2013 [citado el $11 \mathrm{de}$ setiembre del 214]. Disponible en: http://www.cancer.gov/ news-events/press-releases/2013/

GeneTargetsMelanoma

Correspondencia: Iván Lozada Requena Dirección: Av. Honorio Delgado 430 SMP. Lima, Perú

Teléfono: (+511) 3190000 anexo 2511

Correoelectrónico:ivan.lozada@upch.pe

\section{http://www.ins.gob.pe/rpmesp}

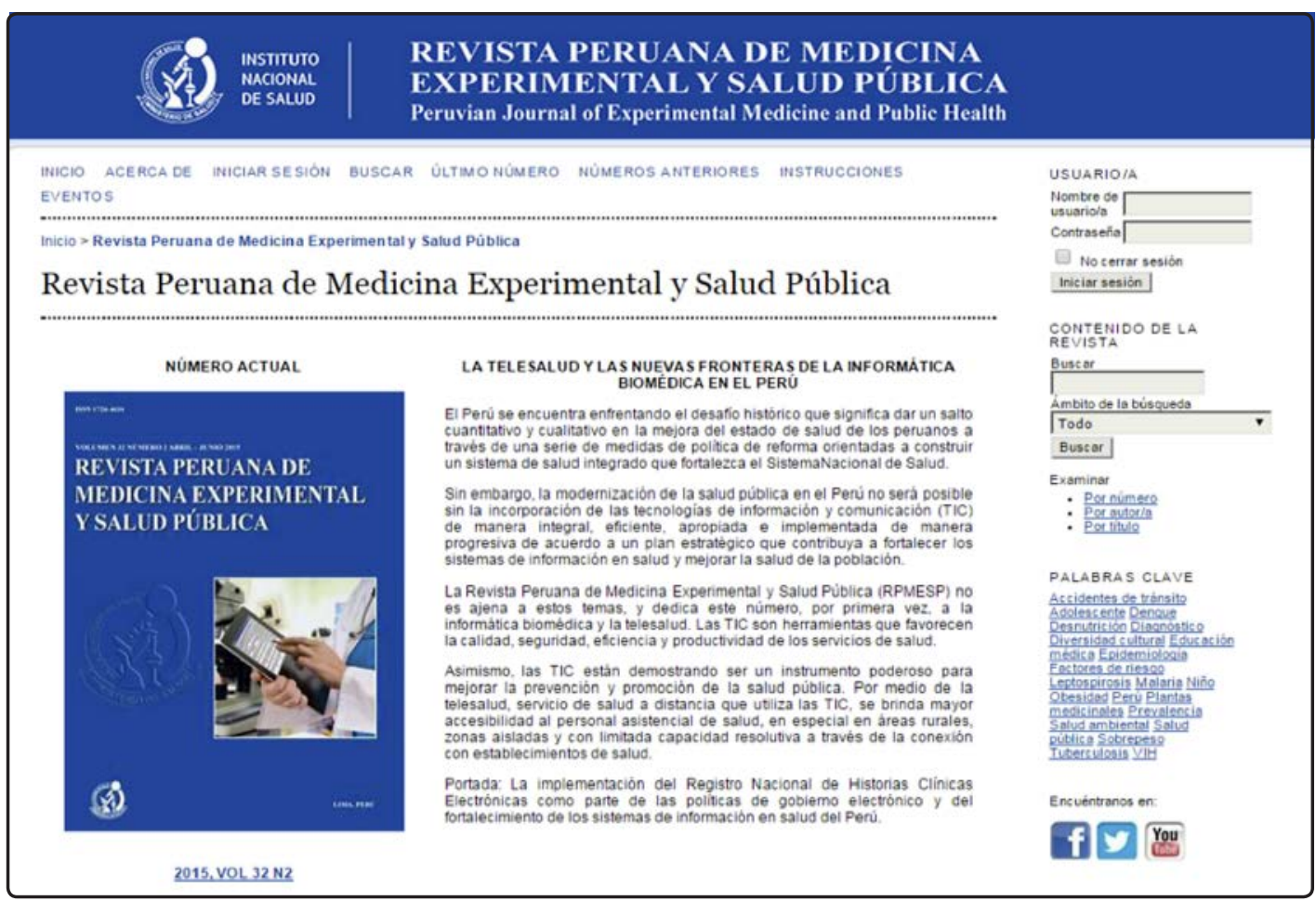

